\title{
Distribution of unit forces on the tool edge rounding in the case of finishing turning
}

\author{
Borys Storch • Anna Zawada-Tomkiewicz
}

Received: 25 February 2011 / Accepted: 31 August 2011 /Published online: 23 September 2011

(C) The Author(s) 2011. This article is published with open access at Springerlink.com

\begin{abstract}
An experimental investigation was conducted to determine the effects of tool cutting edge geometry on the cutting forces in finish turning, where the applied feed and depth of cut are small and often comparable with the tool edge radius. If a tool with large tool edge radius is used in finish turning, the ploughing effect begins to determine the machined surface. This paper presents the results of analytical considerations concerning the unit forces on a cutting edge. The aim of this paper is to indicate possibilities of modelling the unit forces and stress distribution based on cutting resistance. The forces calculated in the feed and cutting speed directions were projected onto the tangential and normal directions of the rounded cutting edge surface. An important assumption in all the considerations was that the thermo-mechanical properties of the materials used remained constant. The minimum thickness of cut was defined, and some characteristic points were identified dividing the cutting zone into three subregions: where a chip is formed, where the machined surface is formed and an unstable region.
\end{abstract}

Keywords Cutting model $\cdot$ Cutting force $\cdot$ Unit force distribution $\cdot$ Rounded cutting edge $\cdot$ Orthogonal turning

$\begin{array}{ll}\text { Nomenclature } \\ a_{\mathrm{p}} & \text { Depth of cut } \\ r_{\mathrm{n}} & \text { Cutting edge radius } \\ h & \text { Thickness of cut layer } \\ h_{\mathrm{i}} & \text { Thickness of cut layer in i-cross section } \\ h_{\mathrm{min}} & \text { Minimal thickness of cut layer }\end{array}$

B. Storch · A. Zawada-Tomkiewicz $(\bowtie)$

Koszalin University of Technology,

Koszalin, Poland

e-mail: anna.zawada-tomkiewicz@tu.koszalin.pl

\author{
$f \quad$ Rate of feed \\ $\phi \quad$ Shear angle \\ $\psi_{\mathrm{i}} \quad$ Angle in i-cross section \\ $\sigma \quad$ Normal stress in a cross section perpendicular to \\ the cutting edge \\ $\tau \quad$ Tangential stress in a cross section perpendicular \\ to the cutting edge \\ $A_{\mathrm{f}}, A_{\mathrm{c}} \quad$ Directional coefficients in equations $F_{\mathrm{f}}=f(h)$ and \\ $F_{\mathrm{c}}=f(\mathrm{~h})$ \\ $F_{\mathrm{f}} \quad$ Feed force \\ $F_{\mathrm{c}} \quad$ Cutting force \\ $F_{\mathrm{N}} \quad$ Normal force in a cross section perpendicular to \\ the cutting edge \\ $F_{\mathrm{T}} \quad$ Tangential force in a cross section perpendicular to \\ the cutting edge
}

\section{Introduction}

In the fundamental machining investigations carried out by Zorev [1] and continued by Hayajneh et al. [2] and Astakhov [3], primary attention has been paid to modelling the geometrically simple orthogonal cutting process involving two-dimensional plastic deformation. Oxley [4] explains the basics of the process of material removal for a simple case of cutting. At the same time, his research shows that although in practice tools with more geometrically complex shapes are used in processing, the cutting mechanism remains the same.

In machining process models, it is assumed that the tool is perfectly sharp (Fig. 1a). The first to propose such a model was Marchant [5]. In the machining model, the tool was infinitely sharp with a shearing plane located at the angle $\phi$. However, cutting tools have a natural roundness of 


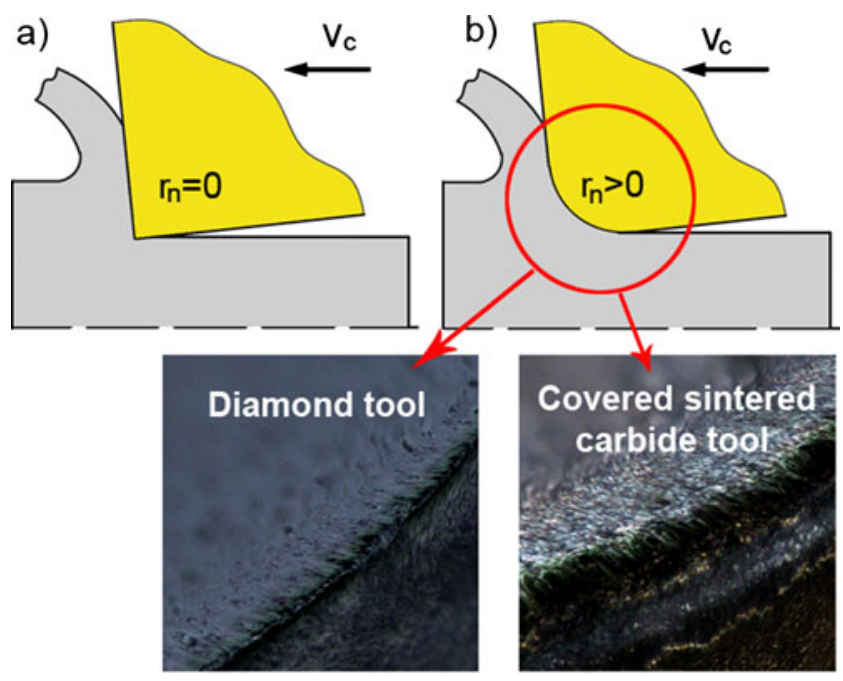

Fig. 1 Cutting edge configurations: a sharp edge, b rounded cutting edge (images of edge rounding-Eclipse MA200×20)

edges (Fig. 1b). For a diamond tool, the natural roundness is less than several micrometres, while for a sintered carbide tool, the roundness is several tens of times greater. A large radius cutting edge makes it stronger and more resistant to chipping. Nevertheless, in precision cutting applications when the thickness of the cut layer is comparable to the cutting edge radius, the ploughing or rubbing action can be substantial and the accuracy of cutting deteriorates [6]. A rounded cutting edge can affect significantly both the forces and temperatures during cutting, especially at chip thicknesses at or below the cutting edge radius. The problem is how to assess the effect of nose radius on the accuracy of the cutting process, especially when cutting thin layers.

In the case of orthogonal free cutting, the resulting machined surface is formed by the active part of the tool moving along the helix. Without movement in the feed direction, the tool's cutting comes to an end after one revolution of the part. When the thickness of the cut layer is smaller than the thickness, below which it is unable to form a chip, the tool's active part elastically and plastically deforms the surface of the machined part.

When the feed is switched off, the cutting force drastically decreases until chip decay. First, the cutting force remains at a small value, then after the decay of plastic deformation, its value decreases, and finally, it ceases completely after the disappearance of the elastic and friction phenomena.

The above reasoning is illustrated in Fig. 2. This diagram shows a field of forces on the cutting edge rounding. It is clear that if the thickness of cut is less than the minimum thickness (Fig. 2, point 1), then the tangential forces on the edge rounding may only have a sense consistent with the direction of the flow of the work material around the rounding.
If we assume that the tool moves, then the relative movements influence the sense of the normal and tangential forces on the edge rounding. To allow the simultaneous movement of both elements of cut toward the flank and rake faces, there must be a point 3 (Fig. 2) of cut layer separation. The thickness of cut corresponding to this point is called the minimum thickness.

During turning, the layer located below the minimum value $\left(h_{\min }\right)$ moves under the lowest point on the edge; hence, it is subjected to strong plastic deformations. The dimension after the passing of the tool is, therefore, the depth difference between the surface of the base and the one newly formed after the pass of the tool. This dimension is created as a composite of two elements: the residual, plastically deformed thickness of cut and deeper located part of the material, which returns elastically after the tool pass. It is difficult to estimate the actual value of the depth of cut, different from the theoretical one, because its value is largely determined by the properties of the work material.

The literature on metal cutting includes several attempts to capture the effect of tool edge geometry on the mechanics of the cutting process, and particularly to explain the phenomenon of ploughing that accompanies the process when a tool features a considerable edge radius.

Yen et al. defined the ploughing ratio as the amount of workpiece material that flows under the cutting edge [7]. They demonstrated that the ploughing ratio depends on the predicted cutting force ratio Fc/Ft. Thiele and Melkote [8] and Kang et al. [9] confirmed that the cutting edge geometry has a significant effect on the cutting force components. Karpat and Özel investigated the friction characteristics of tools with curvilinear edges [10]. They demonstrated the influence of the size of the edge radius on the mechanics of cutting. Özel, by experimental and model investigations, showed the influence of cutting edge geometry on chip formation, forces, temperatures, stresses and tool wear [11]. Variable edge design was considered beneficial in reducing the heat generation and stress concentration along the tool cutting edge. The conclusion drawn from the above research is that force and stress

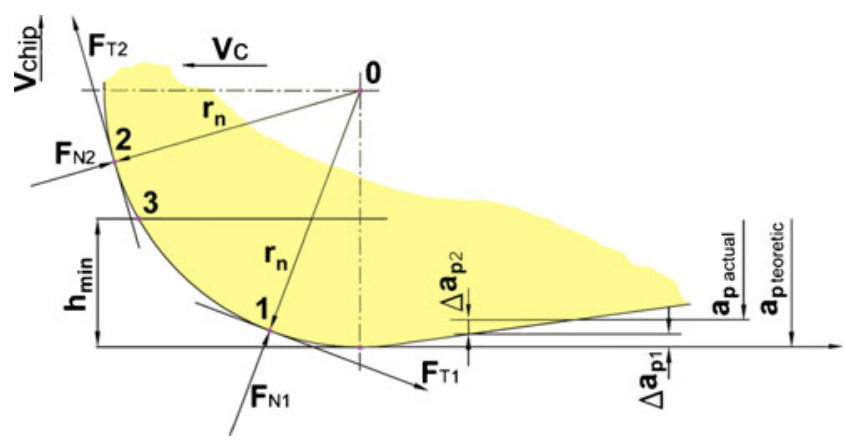

Fig. 2 Force field acting on the rounding of a cutting edge 
distribution in the vicinity of the tool edge has its source in the tool edge geometry.

Nevertheless, the possibility of measuring force components on the tool edge is very limited. Liu et al. stated that the problem of minimum chip thickness estimation is a key factor in the characterization of machining at reduced size scales [12]. The majority of the work has been experimental in nature and little work can be found that deals with the thermal aspects. Guo and Chou examined the extrapolation of cutting force to zero uncut chip thickness [13]. They confirmed that the extrapolation method may be suitable to determine the ploughing force, which is also dependent upon cutting speed with a possible non-linear relationship. However, Ranganath et al. demonstrated that the ratio of chip thickness to ploughing forces remains identical for materials being machined at identical cutting speed [14]. In more than 200 carefully designed cutting experiments, Fang and Wu demonstrated that work material properties play an important role in machining [15]. Liu et al. [16] made an attempt to take account of the temperature conditions in determining the normalized minimum chip thickness. Their research confirms that the thermalmechanical properties of the work material play an important role in micromachining. At the same time, their model is very theoretical. It can be concluded from all the above that both the mechanical and thermal properties of work materials must be considered when constructing a cutting model.

The presented research, devoted to unit forces on the tool edge rounding, develops the model proposed earlier by Storch [17]. In his research, a model for an analytical solution of force distribution on the rounded cutting edge was introduced. The model was based on the assumption that work material properties and tool material and geometry remained the same during cutting.

In this study, the assumption was reflected by maintaining constant temperature conditions during cutting. The unit force and stress distributions in the vicinity of the cutting edge were modelled, and were calculated based on measurement of the components of cutting resistance. For this purpose, the increments of forces calculated in the direction of feed and cutting speed were used, which were then projected onto the tangential and normal directions of the rounded cutting edge surface. As a result of those transformations, nonlinearities of unit force distribution were revealed.

\section{Model description}

In orthogonal free cutting, the shearing phenomena connected with chip formation operate in the same way. This is due to the fact that the thickness of the cut layer is identical in all cross sections orthogonal to the cutting edge. In order to fully describe the shearing phenomena, therefore, it is enough to describe it for one cross section.
To be able to obtain the process of cutting, it is necessary to use cutting forces. Values of the forces $F_{\mathrm{f}}$ and $F_{\mathrm{c}}$ can be measured on a base of cutting resistance with the use of a force gauge. The main assumption in the construction of the cutting model is that constant temperature conditions were preserved regardless of changes in the cutting parameters. The evaluation of forces in such conditions was then performed when the mechanical properties of tool and chip interface are preserved with an additional assumption of constant tool geometry.

Under these assumptions, the stresses and mechanical properties in the vicinity of a rounded tool cutting edge are steady. This assumption constitutes a basis for the linear nature of the forces as a function of the thickness of the cut layer, given as a system of equations.

$\left\{\begin{array}{l}F_{\mathrm{c}}=A_{\mathrm{c}} \times h+B_{\mathrm{c}} \\ F_{\mathrm{f}}=A_{\mathrm{f}} \times h+B_{\mathrm{f}}\end{array}\right.$

These equations are said to be characteristic, with the directional coefficients $A_{\mathrm{c}}$ and $A_{\mathrm{f}}$ describing the resistivity of the cut material in the $v_{\mathrm{c}}$ and $f$ directions for a fixed cutting temperature. The free terms $\left(B_{\mathrm{c}}\right.$ and $\left.B_{\mathrm{f}}\right)$ in the expression 1 correspond to the situation where the thickness of the cut layer is equal to zero. They describe the roundness of cutting edge in relation to the thickness of the cut layer, main wedge angles, its chipness and roughness.

Assignation of forces for cut layer thicknesses $h_{\mathrm{i}}$ and $h_{\mathrm{i}-1}$ allows the increments of forces to be established:

$\Delta F_{c}=\left(A_{\mathrm{c}} \times h_{\mathrm{i}}+B_{\mathrm{c}}\right)-\left(A_{\mathrm{c}} \times h_{\mathrm{i}-1}+B_{\mathrm{c}}\right)=A_{\mathrm{c}} \times \Delta h$

$\Delta F_{\mathrm{f}}=\left(A_{\mathrm{f}} \times h_{\mathrm{i}}+B_{\mathrm{f}}\right)-\left(A_{\mathrm{f}} \times h_{\mathrm{i}-1}+B_{\mathrm{f}}\right)=A_{\mathrm{f}} \times \Delta h$

The increments $\Delta F_{\mathrm{c}}$ and $\Delta F_{\mathrm{f}}$ can be interpreted as unit forces acting on the thickness of the machined layer with $\Delta h=h_{i-1}-h_{i}$ (Fig. 3).

It can be assumed that along the cutting edge in each normal cross section to the cutting edge, the increments of force $\Delta F_{\mathrm{ci}}$ and $\Delta F_{\mathrm{fi}}$ can be determined from Eqs. 2 and 3.

For each part of the tool edge rounding, the unit forces are projected on the tangential and normal directions as shown in Fig. 3.

The vector sum of $\Delta F_{\mathrm{c}}$ and $\Delta F_{\mathrm{f}}$ after the transformation can be defined as:

$$
\begin{aligned}
\Delta F_{\mathrm{T}} & =\mu \Delta F_{1}=\Delta F_{\mathrm{ci}} \cos \psi_{\mathrm{i}}-\Delta F_{\mathrm{fi}} \sin \psi_{\mathrm{i}} \\
& =A_{\mathrm{c}} \Delta h_{\mathrm{i}} \cos \psi_{\mathrm{i}}-A_{\mathrm{f}} \Delta h_{\mathrm{i}} \sin \psi_{\mathrm{i}} \\
\Delta F_{\mathrm{N}} & =\Delta F_{1}=\Delta F_{\mathrm{ci}} \sin \psi_{\mathrm{i}}+\Delta F_{\mathrm{fi}} \cos \psi_{\mathrm{i}} \\
& =A_{\mathrm{c}} \Delta h_{\mathrm{i}} \sin \psi_{\mathrm{i}}+A_{\mathrm{f}} \Delta h_{\mathrm{i}} \cos \psi_{\mathrm{i}}
\end{aligned}
$$




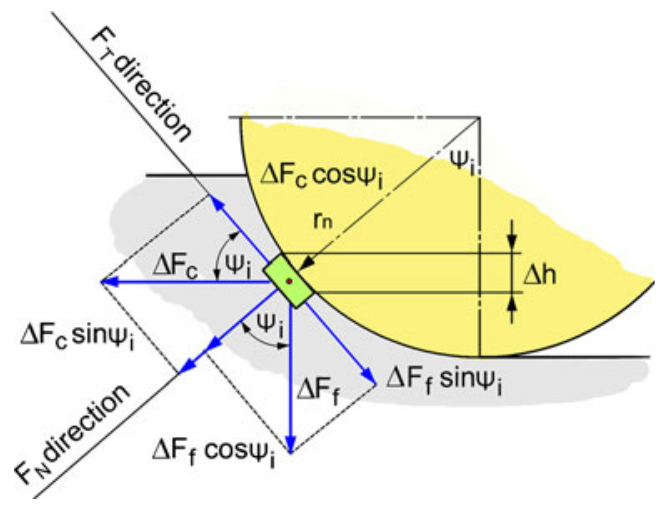

Fig. 3 Scheme of unit forces acting on a particular element of the cutting edge rounding

where $\mu \Delta F_{1}$ is the tangential force determined as the product of normal force $\Delta F_{1}$ and friction coefficient $\mu, \psi_{\mathrm{i}}$ is a polar coordinate determining the location of the centre part of the element on the tool edge rounding.

The algebraic expression 4 determines the value of the tangential force. It takes the value zero at a point where the machined layer is being sheared. With the assumption $\Delta F_{\mathrm{T}}=0$, the expression 4 establishes the critical value of the angle $\psi=\psi_{\text {critical }}$

$A_{\mathrm{c}} \Delta h \cos \psi_{\text {critical }}-A_{\mathrm{f}} \Delta h \sin \psi_{\text {critical }}=0$, then $\psi_{\text {critical }}=\operatorname{arcctg} \frac{A_{\mathrm{f}}}{A_{\mathrm{c}}}$

Equation 6 defines the polar coordinate of the location where the thickness of the cut layer is minimal. This point defines the favourable conditions for chip forming.

The cutting edge operation is similar in each $h_{\mathrm{i}}$ cross section. There can be defined a minimal thickness of the cut layer $h_{\min }$ for which the conditions of conversion of the

Fig. 4 Model and implementation of orthogonal cutting

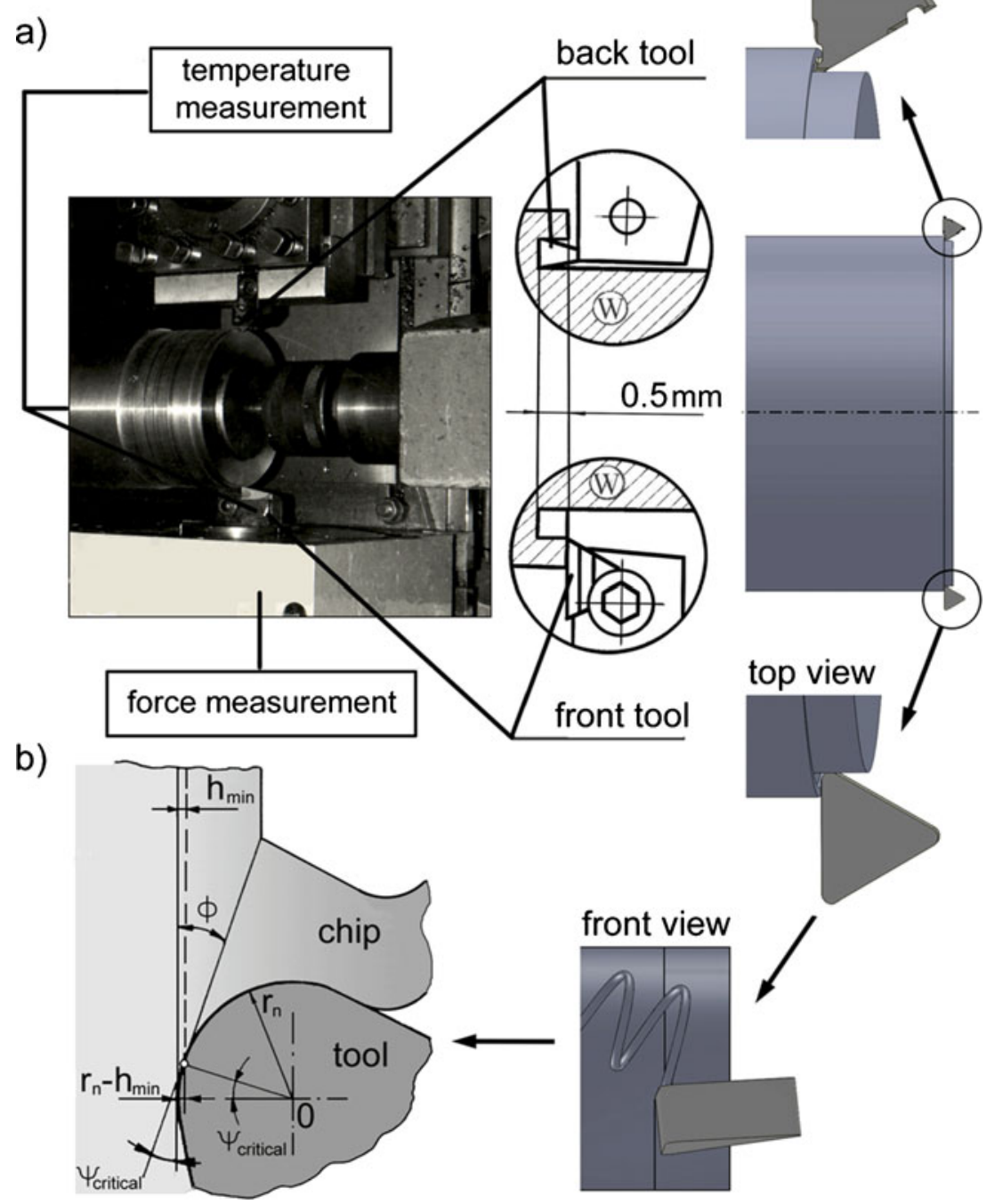


layer into chip are limited. For such conditions an expression taking into account $\psi_{\text {critical }}$ can be written:

$h_{\text {min }}=r_{\mathrm{n}}\left(1-\cos \psi_{\text {critical }}\right)=r_{\mathrm{n}}\left[1-\cos \left(\operatorname{arcctg} \frac{A_{\mathrm{f}}}{A_{\mathrm{c}}}\right)\right]$

where $A_{\mathrm{f}}$ and $A_{\mathrm{c}}$ are directional coefficients in the equations $\Delta F_{\mathrm{f}}=f(\mathrm{~h})$ and $\Delta F_{\mathrm{c}}=f(\mathrm{~h})$, respectively. This is the expression that makes the so-far insoluble problem of the minimum cut layer thickness $h_{\min }$, a phenomenon definable in the machining process.

\section{Experimental procedure}

Experimental methodology was proposed to determine the forces in the cutting zone. Unit force distribution and values were established based on force measurements in orthogonal cutting. First, a research station was built to create the conditions for orthogonal turning (Fig. 4).

Two cutting tools were used. The front tool was fastened on the force gauge for obtaining force and temperature characteristics. The back tool was applied only to achieve the conditions for orthogonal turning. Testing was also performed to check that turning with the use of front tool was not affected by the heat produced by the back tool. The station made it possible to measure forces for orthogonal

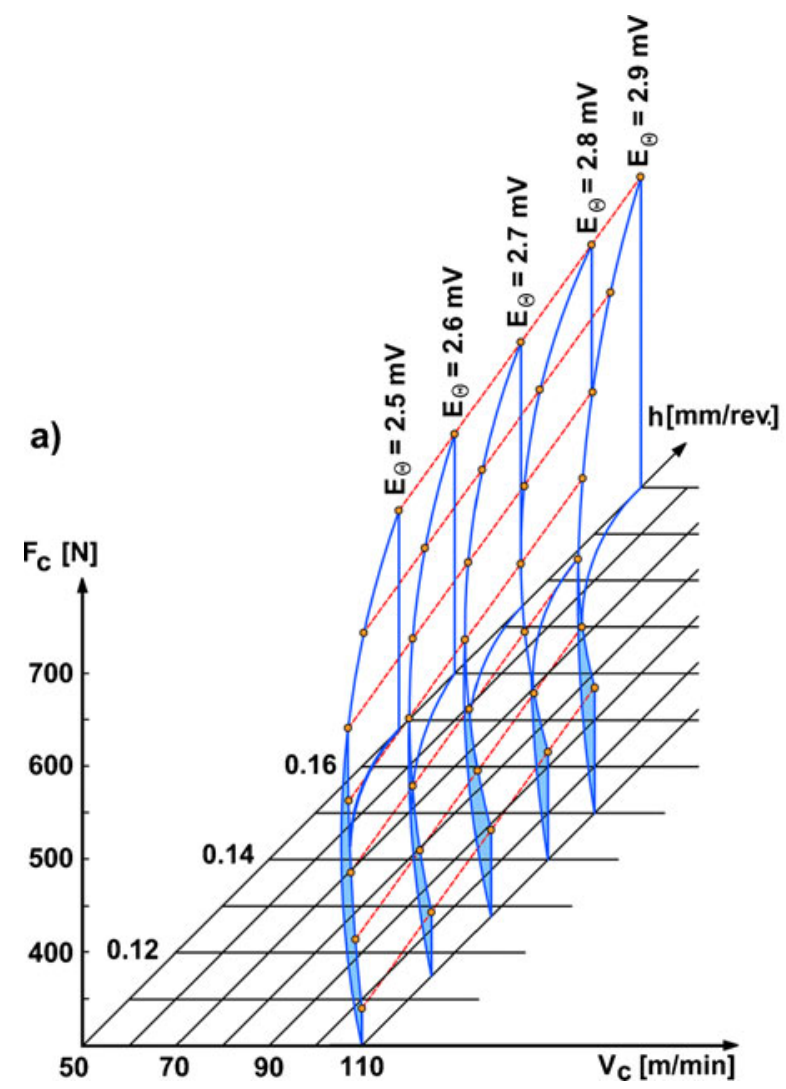

turning on a workpiece with a length of $700 \mathrm{~mm}$ and a diameter of $200 \mathrm{~mm}$.

C55 steel of hardness $220 \mathrm{HB}$ was used as the work material. Sintered carbides S10S were used as the tool material. The tool edge radius was measured with a specially equipped stylus profilometer, and was equal to $0.04 \mathrm{~mm}$. Other tool geometry parameters were $\alpha_{\mathrm{f}}=6^{\circ}, \alpha_{\mathrm{p}}=$ $0^{\circ}, \gamma_{\mathrm{f}}=0^{\circ}, \kappa_{\mathrm{r}}=90^{\circ}, \kappa_{\mathrm{r}}^{\prime}=30^{\circ}$ and $r_{\varepsilon}=0.8 \mathrm{~mm}$. The experiment was performed with a variable feed rate $(0.08$ $0.3 \mathrm{~mm} / \mathrm{rev})$ and cutting speed $(50-130 \mathrm{~m} / \mathrm{min})$. Depth of cut was established by the cutting of the back tool and was equal to $1 \mathrm{~mm}$. All the data points in the experiment (i.e. four feed rate settings and nine cutting speed settings) were calculated based on four repetitions.

Figure 5 summarizes the values of cutting forces as a function of cutting speed and thickness of cut (for free cutting, thickness of cut is equal to feed rate). The forces are presented on a background of constant thermocouple voltage $E_{\Theta}$ (of nonlinear waveform). It can be observed that the thermocouple voltage increase is accompanied by an increase in the cutting forces. Nevertheless, a constant predetermined value of thermocouple voltage can be obtained only for a precisely defined set of cutting parameters. Hence, it is concluded that the most important aspect of the presented charts is that there is a possibility of controlling the temperature conditions knowing only the cutting parameters.

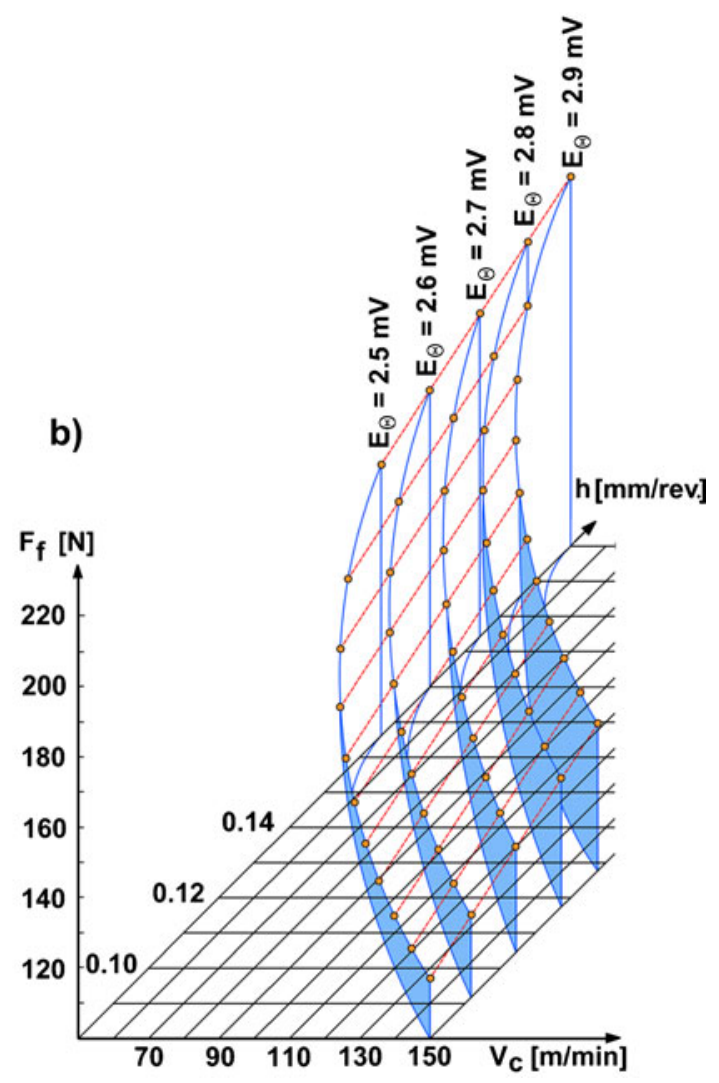

Fig. 5 Forces as a function of cutting parameters for constant $E_{\Theta}$ 


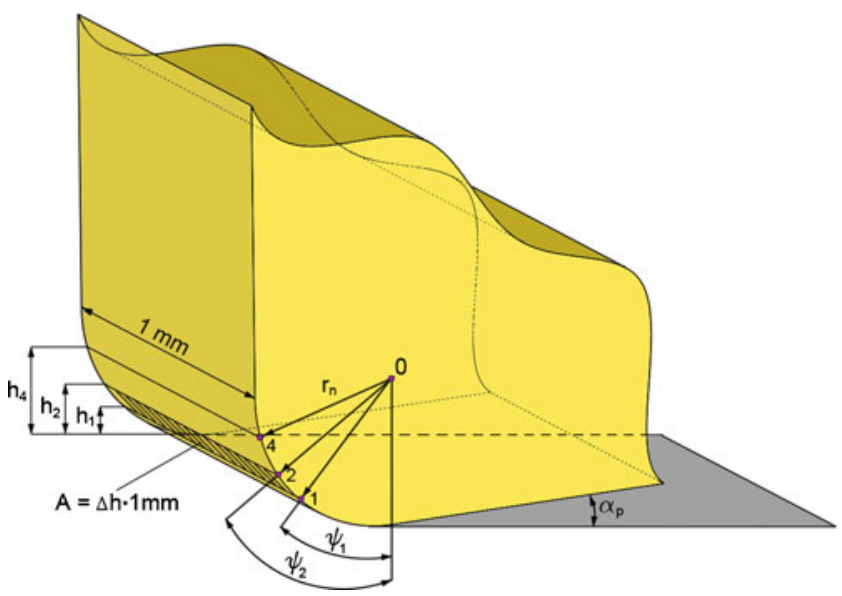

Fig. 6 Variation of cut layer thickness for cutting edge radius $r_{\mathrm{n}}$

\section{Distribution of unit forces in the cutting zone}

The primary assumption throughout the research was that fixed temperature conditions would be maintained. In order to provide conditions of constant temperature, an experiment was designed in which the thermocouple voltage in the cutting zone was measured for variable thickness of cut and cutting speed. In orthogonal free cutting, the cut layer thickness is equal to the feed rate, which varies as shown in Fig. 5. With variable thickness of cut, the cutting speed was changed as well. The results made it possible to create a set of constant temperature conditions. Constant temperature preserves the values of the parameters of characteristic Eq. 1 at the same level.

The second assumption is a result of analysis of the orthogonal cutting principle. It states that the thicker cross section of the cut layer contains all the thinner cross sections. This is an assumption which enables the measurement of cutting forces in constant temperature conditions.

The above two assumptions ensure the invariance of cutting phenomena in the vicinity of the cutting edge
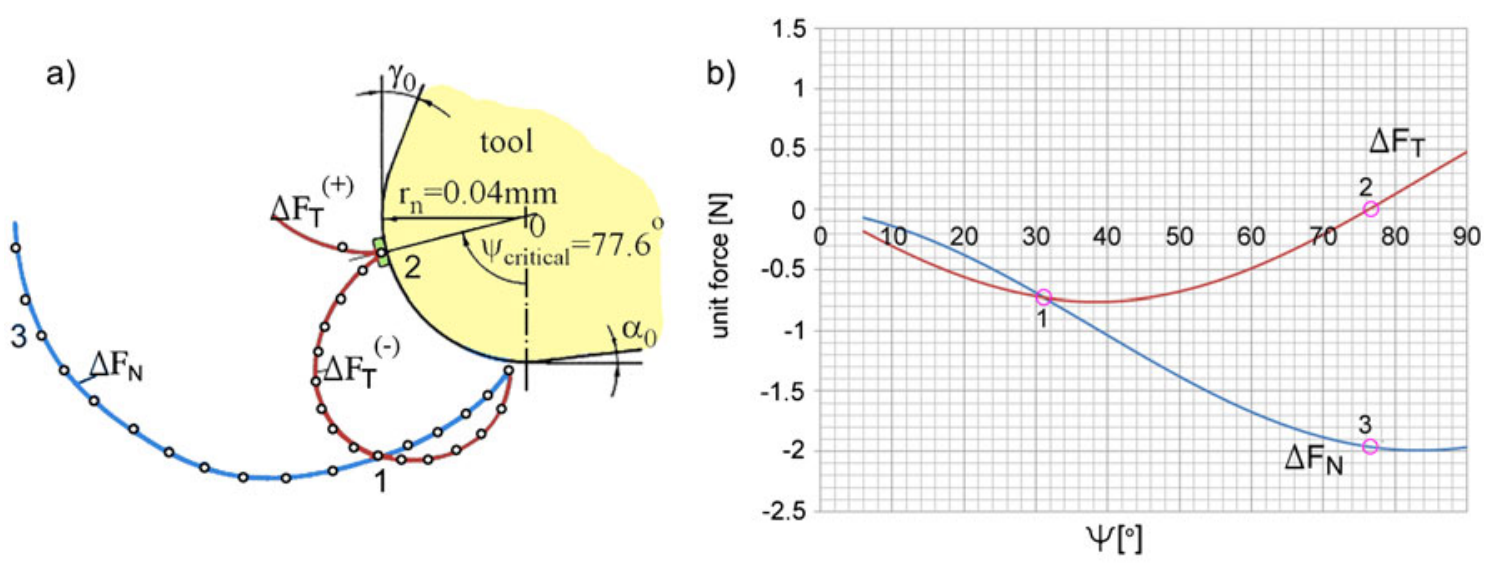

Fig. 7 Distribution of unit forces $\Delta F_{\mathrm{T}}$ and $\Delta F_{\mathrm{N}}$ a in a cross section perpendicular to the cutting edge, $\mathbf{b}$ distribution of unit forces in a Cartesian coordinate system as a function of angle $\psi$ 


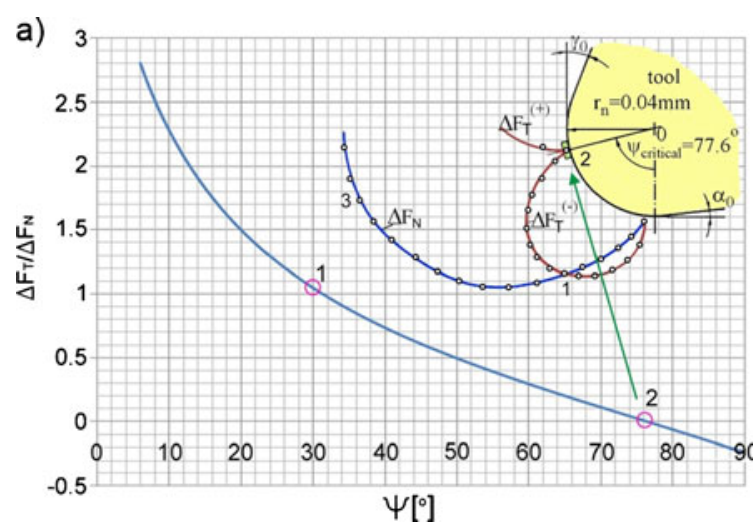

Fig. 8 Value of 'friction coefficient' computed as the relation $\Delta F_{\mathrm{T}} / \Delta F_{\mathrm{N}}$

point 2 (Fig. 7) at angle $\psi$ was computed to be in an interval between $60.1^{\circ}$ and $81.1^{\circ}$, taking into account all the considered conditions. This point separated the cutting edge surface rounding into two parts: attributable to the rake and the flank faces.

The point of cut layer separation (point 2 in Fig. 8) defines the unit force relation in which it has the value of zero (stagnation point or separation point). For higher values of $\psi$, the unit force relation changes its sign (a chip is formed). For smaller values of $\psi$, the unit force relation describes what is happening with the rest of the work material. Point 1 (Fig. 8) represents the situation where the tangential and normal forces are of the same value. When the tangent force is higher than the normal force, the work material moves around the tool edge rounding in a direction opposite to the chip. In the interval between points 1' and 2 (Fig. 8), the unit normal force is larger than the unit tangential force. In this range of $\psi$, the work material can behave in an unstable manner. The work material can change into a chip or can move around the cutting edge rounding and form the machined surface.

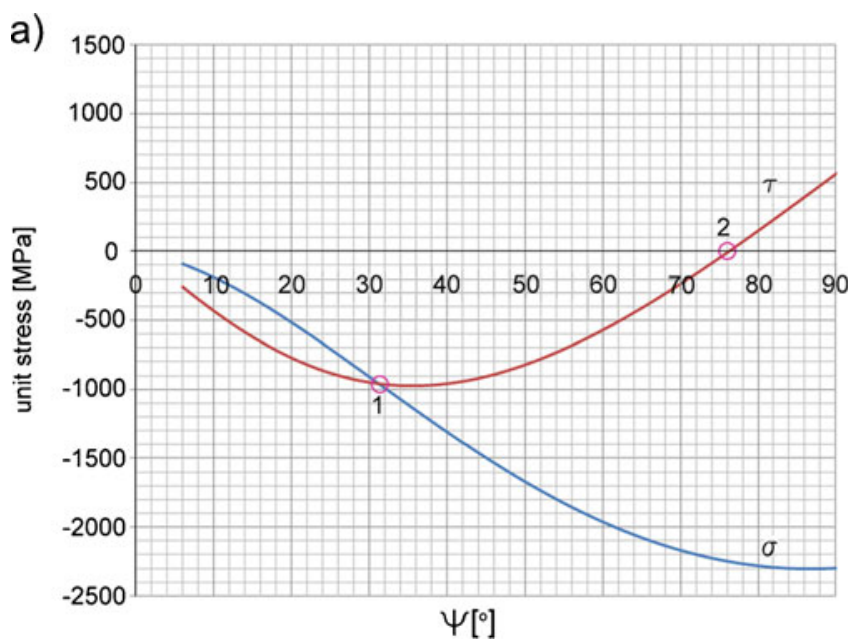

Fig. 9 Variation of unit $\tau$ and $\sigma$ stress on the cutting edge rounding

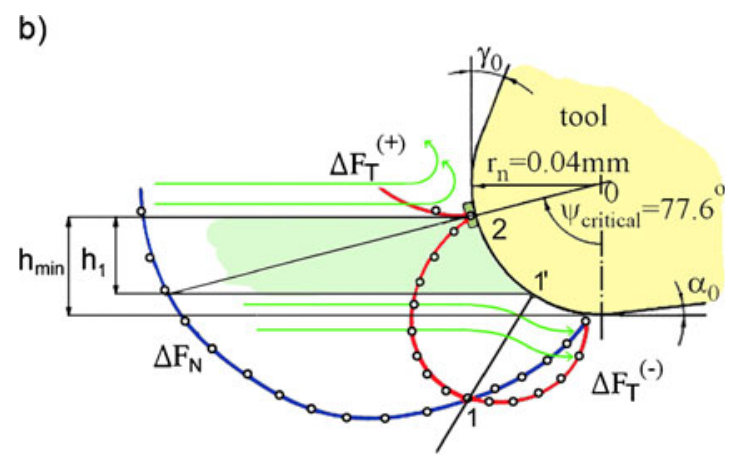

\section{Distribution of shear stress in the cutting zone}

To determine the unit stress on the rounded cutting edge, the values of unit tangential and unit normal forces were divided by the field on which these forces act. As a result of the calculation, the unit tangential and unit normal stresses were obtained, as presented in Fig. 9a.

The established unit stress values of $\tau$ and $\sigma$, obtained by dividing the unit forces by their field of action, exceeded 2,000 MPa and showed variability like that of the unit $\Delta F_{\mathrm{T}}$ and $\Delta F_{\mathrm{N}}$ forces. The highest value of unit normal stress $\sigma$ was observed in the vicinity of point 3 (Fig. 9a), which indicates that the machined material, adherent to the cutting edge surface rounding, is situated in the area of stress in which it reaches its strength limit.

The unit $\tau$ and $\sigma$ stresses are of the same value at points 1,2 and 3 (Fig. 9b). Taking into account that the considerations concern the same temperature conditions, one can observe that the difference of cut layer thickness of the unstable layer (value of $h_{1}$ in Figs. $8 \mathrm{~b}$ and $9 \mathrm{~b}$ ) changes depending on the tool edge radius. For a sharp tool with

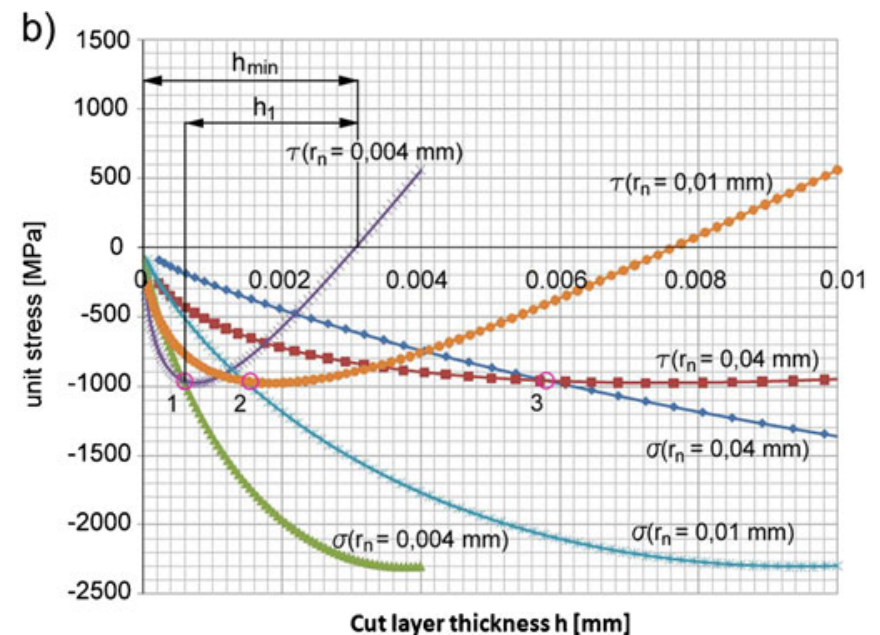


edge having a radius of $4 \mu \mathrm{m}$, the unstable layer can be estimated to be $2.5 \mu \mathrm{m}$. For a blunt tool with an edge having a radius of $40 \mu \mathrm{m}$, the unstable layer is indicated to be much higher, equal to $24 \mu \mathrm{m}$. This unstable layer depends mainly on the tool edge radius, material properties and cutting parameters.

\section{Summary and conclusions}

In this paper, a calculation method was proposed to evaluate the distribution and value of unit normal and unit tangential forces on the rounding of a cutting edge. The experiment was conducted on a specially built laboratory station to obtain conditions of orthogonal cutting with simultaneous measurement of temperature and force components. For constant width of cut layer cross section, steady-state temperature conditions were achieved for different combinations of cutting speed and feed rate. The experimental results were the basis for force calculations in steady-state temperature conditions. The developed analytical model of forces was calculated as a function of feed rate, tool nose radius, edge radius, workpiece and tool material.

Simplification of cutting edge design by using chamfered edges instead of rounded ones had no influence on the correctness of the above considerations, and can lead only to the shortening of tool life due to change of load distribution and, in effect, increased stress concentration on the edge. The abovedescribed model of forces concerns all cases of single-point cutting with a cutting tool of stable geometry.

The distribution of forces along the rounded cutting edge facilitated a more insightful analysis of unit force distribution. Although the courses of determined unit forces were very much diversified, the summation of their values revealed that the computed components of cutting forces were almost identical to those measured. The calculated force models in orthogonal cutting were in agreement with the experiment. The model is particularly valid for finish turning, where the edge radius influences the surface finish.

The distribution of unit normal and tangential forces on the rounding of the cutting edge was of the same character independently of the cutting conditions. Force and stress distribution on the rounding of the cutting edge are nonlinear and independent of the cutting temperature. Nevertheless, the temperature influences the value of the forces.

On the rounding of the cutting edge, a specific point can be identified where only the normal force is non-zero and where the unit tangential force changes its sign. At this point, the shearing conditions of the work material are introduced. Work material located above this point turns into a chip. Work material below this point tends only to be deformed. Additionally, the value of the relation between unit tangential and unit normal forces motivates the distinction of two subregions - with dominant normal force and with dominant tangent force. The first region, called unstable in this study, introduces indefinite cutting conditions. In the second region, the larger values of unit tangential force in relation to unit normal force have a beneficial effect on the flow of material around the cutting edge.

Open Access This article is distributed under the terms of the Creative Commons Attribution Noncommercial License which permits any noncommercial use, distribution, and reproduction in any medium, provided the original author(s) and source are credited.

\section{References}

1. Zorev NN (1966) Metal cutting mechanics. Pergamon Press, Oxford

2. Hayajneh MT, Astakhov VP, Osman MOM (1998) An analytical evaluation of the cutting forces in orthogonal cutting using a dynamic model of the shear zone with parallel boundaries. J Mater Process Tech 82(1-3):61-77

3. Astakhov VP (1999) Metal cutting mechanics. CRC Press, Boca Raton, FL

4. Oxley PLB (1989) The mechanics of machining: an analytical approach to assessing machinability. Ellis Horwood, England

5. Merchant ME (1944) Basic mechanics of the metal cutting process. J Appl Mech Trans Am Soc Mech Eng 66:168

6. Fang FZ, Zhang GX (2003) An experimental study of edge radius effect on cutting single crystal silicon. Int J Adv Manuf Technol 22:703-707

7. Yen Y-Ch, Jain A, Altan T (2004) A finite element analysis of orthogonal machining using different tool edge geometries. J Mater Process Tech 146:72-81

8. Thiele JD, Melkote SN (1999) Effect of cutting edge geometry and workpiece hardness on surface generation in the finish hard turning of AISI 52100 steel. J Mater Process Tech 94:216-226

9. Kang IS, Kim JS, Seo YW (2008) Cutting force model considering tool edge geometry for micro and milling process. $\mathrm{J}$ Mech Sci Tech 22:293-299

10. Karpat Y, Özel T (2008) Mechanics of high speed cutting with curvilinear edge tools. Int J Mach Tools Manuf 48:195208

11. Özel $T$ (2009) Computational modelling of 3D turning: Influence of edge micro-geometry on forces, stresses, friction and tool wear in PcBN tooling. J Mater Process Tech 209:5167-5177

12. Liu X, DeVor RE, Kapoor SG, Ehmann KF (2004) The mechanics of machining at the microscale: assessment of the current state of the science, Transactions of the ASME 126:666-678

13. Guo YB, Chou YK (2004) The determination of ploughing force and its influence on material properties in metal cutting. J Mater Process Tech 148:368-375 
14. Ranganath S, Campbell AB, Gorkiewicz DW (2007) A model to calibrate and predict forces in machining with honed cutting tools or inserts. Int J Mach Tools Manuf 47:820-840

15. Fang N, Wu Q (2005) The effects of chamfered and honed tool edge geometry in machining of three aluminum alloys. Int J Mach Tools Manuf 45:1178-1187
16. Liu X, DeVor RE, Kapoor SG (2006) An analytical model for the prediction of minimum chip thickness in micromachining. $\mathrm{J}$ Manuf Sci Eng 128:474-481

17. Storch B (1989) Wzajemne oddziaływanie naroża ostrza i materiału skrawanego. Wydawnictwo Politechniki Wrocławskiej, Wrocław 